\title{
Acceptance of pharmaceutical cannabis substitution by cannabis using patients with schizophrenia
}

\author{
Jan van Amsterdam ${ }^{1 *}$ (D), Jojanneke Vervloet ${ }^{2}$, Gerdien de Weert ${ }^{2}$, Victor J. A. Buwalda², Anna E. Goudriaan ${ }^{1,2}$ \\ and Wim van den Brink
}

\begin{abstract}
Background: Cannabis-smoking patients with a psychotic disorder have poorer disease outcomes than non-cannabissmoking patients with poorest outcomes in patients smoking high-potency cannabis (HPC) containing high $\triangle 9$-tetrahydrocannabinol (THC) and low cannabidiol (CBD). Quitting cannabis smoking or substitution of HPC by cannabis variants containing less THC and/or more CBD may benefit these patients. The present study explores whether daily HPC-smoking patients with schizophrenia accept smoking such variants.

Methods: Twelve male patients were asked to smoke on six different occasions one joint: on two occasions, the cannabis they routinely smoke (HPC; not blind), and blind in random order; on two occasions, cannabis containing low THC and no CBD; and on two occasions, cannabis containing low THC and high CBD.

Results: Both substitute variants were appreciated, but patients preferred the HPC they usually smoked. The effect of the low THC/high CBD variant was reported by $32 \%$ to be too short and by $36 \%$ to be not strong enough, whereas this was reported by $5 \%$ and $64 \%$, respectively, for the low THC cannabis variant.
\end{abstract}

Conclusions: Based on these findings, a larger and longer study on the efficacy of cannabis substitution treatment in HPC-smoking patients with schizophrenia seems feasible and should be considered.

Trial registration: 2014-005540-17NL. Registered 22 October 2014, 2014-005540-17NL 20141215 CTA.xml

Keywords: Schizophrenia, Psychosis, Cannabis, Skunk, CBD, High-potency cannabis

\section{Introduction}

Prevalence of cannabis use in patients with a psychotic disorder is high $[1,2]$. According to patients, cannabis is often used as self-medication to ameliorate positive and/or negative symptoms [3], to get "high," and/or for pleasure and social motives [4-6]. However, there is growing evidence that (a) patients with a psychotic disorder who smoke high-potency cannabis (HPC), i.e., cannabis containing high concentrations of $\Delta 9$-tetrahydrocannabinol (THC) and low concentrations of cannabidiol (CBD), have poorer disease outcomes than either non-cannabis-smoking patients or patients that discontinue their cannabis use and (b) patients who continue the use of HPC

\footnotetext{
* Correspondence: jan.van.amsterdam@amc.uva.nl; vanamsterdam@gmx.net ${ }^{1}$ Department of Psychiatry, Academic Medical Center, University of Amsterdam, P.O. Box 22660, 1100 DD Amsterdam, The Netherlands Full list of author information is available at the end of the article
}

show more psychotic episodes and an increased probability of (re)hospitalization [7, 8].

THC seems to be the main driver of the psychotogenic effects of cannabis, whereas CBD may inhibit THCinduced anxiety and psychosis. In a large web-based cross-sectional survey, it was shown that persons who smoked cannabis with a low THC/CBD ratio had significantly fewer psychotic-like experiences than those smoking cannabis with higher THC/CBD ratios [9]. Furthermore, co-administration of CBD and THC induced less anxiety and fewer psychotic-like symptoms than THC alone [10-14], implicating that smoking CBD-enriched cannabis (and containing less THC) may be less harmful for patients with a psychotic disorder who do not want or cannot quit smoking cannabis [13, 14]. Therefore, prescribing cannabis containing less THC and/or more CBD as a substitution for HPC is a 
promising form of harm reduction, i.e., allowing the use of cannabis and simultaneously reducing the risk of psychotic episodes and (re)hospitalization. In the current study, we investigated whether patients with a psychotic disorder using HPC accept smoking less harmful cannabis variants, i.e., cannabis variants with less THC and/or more CBD.

\section{Methods}

\section{Study design}

The cannabis that patients regularly smoked ("own cannabis") was used as a reference to evaluate the acceptability of two medicinal cannabis variants containing less THC. In the presence of the investigator, patients smoked one joint on six separate days. The cannabis $(0.25 \mathrm{~g})$ was rolled in tobacco. The first and last joint contained the patient's own cannabis. The other four joints were offered in a blinded and random order and contained either $0.25 \mathrm{~g}^{\circ}$ Bediol $^{\odot}$ (3.6\% $w / w$ THC and 7.1\% $w / w$ CBD; two times) or $0.25 \mathrm{~g}$ of Bedrobinol $^{\bullet}(9.1 \% w / w$ THC and $<0.2 \% w / w$ CBD; two times). For product details about Bedrobinol and Bediol, please see the website of the Office Medicinal Cannabis (BMC) [15]. The patient's own cannabis was assayed for THC and CBD.

\section{Inclusion criteria}

Twelve male outpatients (mean $40.5 \pm 10.0$ years; range 22-54 years.) who were in treatment for schizophrenia and a comorbid cannabis use disorder were included. All were daily cannabis smokers, currently treated with antipsychotics, and had suboptimal response to treatment, i.e., persistent psychotic symptoms and poor social behavior. One patient dropped out of the study after having smoked two joints (once his own weed and once Bediol $^{\odot}$ ). His refusal to further participate was not linked to the Bediol ${ }^{\circ}$ offered to him or to the aim of the study.

\section{Data collection}

Baseline characteristics included demographics, medication use, use of (illicit) substances (including frequency of cannabis use), motivation to smoke cannabis (specifically as a way to suppress positive and negative symptoms), cannabis craving (Questionnaire on Smoking Urges; QSU-Brief), psychotic-like experiences (CAPE-42), anxiety and depressive symptoms (HADS), and quality of life. It should be noted here that the QSU was developed and tested for tobacco smoking in adolescents and that no reliability and validity data are present for cannabis use and for the current population of patients with a psychotic disorder.

At 15, 60, and 120 min post-smoking, patients completed a questionnaire about their current mood (Profile of Mood States: POMS) [16], and their appreciation of the joint just smoked. For the assessment of the appreciation of the joint, we specifically developed a self-report questionnaire with 16 items scored on a 5-point Likert-type scale ranging from "not at all" to "very much." Examples of these 16 items are "I like this weed," "Strong effect," "Strong kick," "Feeling stoned," "Nice taste," and "I want this weed again." At 120 min post-smoking, the patient was also asked to express (free-text) his opinion about the cannabis just smoked and whether he would be prepared to change in the future from smoking his own cannabis to this cannabis type.

\section{Results}

The patient's own cannabis contained $14.0 \pm 4.6 \% \mathrm{w} / \mathrm{w}$ THC and $0.2 \pm 0.1 \% w / w$ CBD, which compares well with the strength of the most popular cannabis variants sold in Dutch coffee shops [17]. Patients smoked on average $5.5 \pm 5.0$ joints per day, and the mean daily THC dose (mean $170.6 \pm 115.8 \mathrm{mg}$ ) was linearly related to the cannabis craving score $\left(R^{2}=0.42\right)$. CAPE- 42 total score was $131 \pm 36$ and HADS score was $12.6 \pm 8.0$. All patients (also) smoked cannabis for pleasure.

Side effects after smoking each joint were rarely noticed. Psychosis-like signs were not observed, and some transitory nausea and dizziness were only occasionally reported.

The appreciation scores of the three joints (the patient's own cannabis and the two medicinal cannabis variants) are shown in Table 1 and indicate that the patients appreciated and accepted the two medicinal cannabis variants, though less than their own cannabis. The CBD-enriched variant which contained only 3.6\% $w / w$ THC (Bediol ${ }^{\circ}$ ) and the almost threefold stronger Bedrobinol $^{\bullet}(9.1 \% w / w$ THC) was appreciated to the same extent, though Bedrobinol was experienced as "stronger" with a better "kick." Similar trends were seen for the other ten items of the questionnaire (data not shown). The consistency of repeated questions like "I like this weed," and "I want this weed again" was high $(r=0.96)$ indicating good reliability. Based on the scores given for "I like this weed" and "Want this weed again," only limited differences were reported across the three cannabis types tested, whereas the strength and taste of both medicinal cannabis variants were less appreciated than the patient's own cannabis.

In the patients' opinion (given free-text), the two medicinal variants were "Okay," but again, the major complaint was the low strength and-less so-the less nice taste of the two medicinal cannabis variants. Finally, all patients were asked about their willingness to replace their own cannabis (HPC) by one of the two medicinal cannabis variants, but no clear answers were obtained. However, they expressed that a possible transition would 
Table 1 Sensory effects reported at 15, 60, and 120 post-smoking for "Own cannabis," Bediol, and Bedrobinol. Scores presented are the mean values obtained in two separate sessions. In parenthesis: percentage of score with own weed as reference

\begin{tabular}{lllllll}
\hline & I like this weed & Strong effect & Strong kick & Stoned feeling & Nice taste & Want this weed again \\
\hline $\begin{array}{llllll}\text { 15 min } \\
\text { Own weed }\end{array}$ & 2.32 & 3.23 & 1.91 & 2.95 & 3.18 & 2.32 \\
Bediol & $2.50(108 \%)$ & $2.05(63 \%)$ & $1.91(100 \%)$ & $2.55(86 \%)$ & $2.32(73 \%)$ & $2.45(106 \%)$ \\
Bedrobinol & $2.55(110 \%)$ & $2.32(72 \%)$ & $1.95(102 \%)$ & $2.41(82 \%)$ & $2.09(66 \%)$ & $2.27(98 \%)$ \\
60 min & & & & & \\
Own weed & 2.32 & 2.68 & 1.82 & 2.68 & 2.82 & 2.27 \\
Bediol & $2.00(86 \%)$ & $1.64(61 \%)$ & $1.50(82 \%)$ & $1.91(71 \%)$ & $1.64(58 \%)$ & $2.41(106 \%)$ \\
Bedrobinol & $2.00(86 \%)$ & $1.91(71 \%)$ & $1.68(92 \%)$ & $1.95(73 \%)$ & $1.91(68 \%)$ & $1.82(80 \%)$ \\
120 min & & & & & 2.59 & $1.82(70 \%)$ \\
Own weed & 2.27 & 2.73 & 1.45 & $1.09(75 \%)$ & $1.82(77 \%)$ & $1.95(91 \%)$ \\
Bediol & $2.23(98 \%)$ & $1.36(50 \%)$ & $1.55(107 \%)$ & $1.73(73 \%)$ & $1.95(75 \%)$ & $1.95(91 \%)$ \\
Bedrobinol & $2.00(88 \%)$ & $1.82(67 \%)$ & & & \\
\hline
\end{tabular}

heavily depend on experiences during prolonged use and the options for financial reimbursement.

\section{Discussion}

The main finding of this pilot study among 11 daily cannabis-smoking male patients with schizophrenia was that they did not refuse to smoke the two medicinal cannabis variants as an alternative for their own cannabis, although on average, they preferred the cannabis they usually smoked (own cannabis). As such, a larger and prolonged study aiming to convert patients with a psychotic disorder from smoking HPC to cannabis variants enriched in CBD and/or containing less THC is promising and feasible. Probably, cannabis offered to outpatients as an alternative to street cannabis should contain at least $4 \%$ of THC (based on $0.25 \mathrm{~g}$ of cannabis per joint). This is supported by a previous study showing that patients with a psychotic disorder did not accept cannabis containing only $0.4 \% w / w$ THC as an alternative [18]. Obviously, quitting from smoking cannabis would be the best option for patients with a psychotic disorder. However, if patients cannot be motivated to quit cannabis use, continued smoking of cannabis containing less THC (and/or more CBD) may result in lower relapse rates, shorter hospitalization, and better psychological functioning [8]. Note that for patients motivated to stop cannabis use, the "milder" cannabis variant might have been a constructive intermediate step in their process to quit smoking cannabis and would express a higher appreciation of Bediol than their non-motivated counterparts.

A clear limitation of the study was that patients did not smoke the two variants over a prolonged time period, but only twice. Another limitation of this pilot study is that patients in the current study were not blinded to their own cannabis. However, blinding of own cannabis would have been redundant because of its typical smell which is easily recognized by the patient. A third limitation is the absence of any psychotic symptoms during the study indicating that the patients included were well treated with antipsychotic medication. For medical ethical reasons, it is, however, impossible to discontinue their antipsychotic medication. A fourth limitation is all patients were male so that it remains to be established whether female patients would show a similar outcome. Finally, just like tobacco smokers, cannabis users may just be accustomed to their own "brand."

The patients included in this study may be defined as dual diagnosis psychiatric patients with schizophrenia and a substance use disorder. This group of patients usually has a long track of failed treatments, are treatment resistant, have a relatively low quality of life, and are clinically unstable. This group of patients would probably benefit in terms of mental health and well-being if they would use one of the two medicinal cannabis variants tested in the current study. A risk factor for successful cannabis substitution in these patients is that they purchase additional HPC in the coffee shop and smoke it concomitantly with the medicinal cannabis that is prescribed as substitution treatment and thus reimbursed.

In conclusion, our results demonstrate that daily cannabis-smoking patients with a psychotic disorder seem willing to accept smoking cannabis that contains less $\mathrm{THC}$ and/or more $\mathrm{CBD}$ as an alternative for the HPC they usually smoke. As such, attempts to transfer such patients from smoking HPC to less harmful cannabis variants over a prolonged period of time seems promising and feasible. 


\section{Abbreviations}

CAPE: Community Assessment of Psychic Experiences; CBD: Cannabidiol; HADS: Hospital Anxiety and Depression Scale; HPC: High potency cannabis ("skunk"); THC: $\triangle$ 9-tetrahydrocannabinol

\section{Acknowledgements}

The authors thank Hans Post, Laurens Reimert, Monique Staats, Arthur Gerver, Piet Broenland, Ilse Wolterink, Minke Hoogstrate, Ilse Beaufort, Nina Behr, Arno Hazenkamp, Sander Rigter, pharmacy staff members of the A. v. Leeuwenhoek hospital, and the participants for their support.

\section{Funding}

This research was financially supported by the Municipality of Utrecht which had no role in the design, analysis, and report of this study.

\section{Availability of data and materials}

Please contact the corresponding author for data requests.

\section{Authors' contributions}

$J v A, W v d B$, and $J V$ were responsible for the data collection and drafted the manuscript. GdW, VJAB, and AEG participated in the design and coordination of the study and drafting of the manuscript. All authors read and approved the final manuscript.

\section{Ethics approval and consent to participate}

All participants signed an informed consent form. The Medical Ethical Committee of the AMC, University of Amsterdam approved the study. Trial registration: 2014-005540-17NL. Registered 22 October 2014, 2014-00554017NL 20141215 CTA.xml

\section{Consent for publication}

Not applicable.

\section{Competing interests}

The authors declare that they have no competing interests.

\section{Publisher's Note}

Springer Nature remains neutral with regard to jurisdictional claims in published maps and institutional affiliations.

\section{Author details}

'Department of Psychiatry, Academic Medical Center, University of Amsterdam, P.O. Box 22660, 1100 DD Amsterdam, The Netherlands. 2Jellinek-Arkin, P.O. Box 75848, 1070 AV Amsterdam, The Netherlands.

Received: 5 June 2018 Accepted: 4 September 2018

Published online: 20 September 2018

\section{References}

1. Koskinen J, Lohonen J, Koponen H, Isohanni M, Miettunen J. Rate of cannabis use disorders in clinical samples of patients with schizophrenia: a metaanalysis. Schizophr Bull. 2010;36:1115-30.

2. Green B, Young R, Kavanagh D. Cannabis use and misuse prevalence among people with psychosis. Br J Psychiatry. 2005:187:306-13.

3. Spencer C, Castle D, Michie PT. Motivations that maintain substance use among individuals with psychotic disorders. Schizophr Bull. 2002;28:233-47.

4. Gill KE, Poe L, Azimov N, Ben-David S, Vadhan NP, Girgis R, et al. Reasons for cannabis use among youths at ultra high risk for psychosis. Early Interv Psychiatry. 2015:9:207-10.

5. Thornton LK, Baker AL, Lewin TJ, Kay-Lambkin FJ, Kavanagh D, Richmond R, et al. Reasons for substance use among people with mental disorders. Addict Behav. 2012;37:427-34.

6. Schaub M, Fanghaenel K, Stohler R. Reasons for cannabis use: patients with schizophrenia versus matched healthy controls. Aust N Z J Psychiatry. 2008; 42:1060-5.

7. Schoeler T, Monk A, Sami MB, Klamerus E, Foglia E, Brown R, et al. Continued versus discontinued cannabis use in patients with psychosis: a systematic review and meta-analysis. Lancet Psychiatry. 2016;3:215-25.

8. Schoeler T, Petros N, Di Forti M, Klamerus E, Foglia E, Ajnakina O, et al. Effects of continuation, frequency, and type of cannabis use on relapse in the first 2 years after onset of psychosis: an observational study. Lancet Psychiatry. 2016:3:947-53.

9. Schubart CD, Sommer IEC, van Gastel WA, Goetgebuer RL, Kahn RS, Boks MPM. Cannabis with high cannabidiol content is associated with fewer psychotic experiences. Schizophr Res. 2011;130:216-21.

10. Zuardi AW, Shirakawa I, Finkelfarb E, Karniol IG. Action of cannabidiol on the anxiety and other effects produced by delta 9-THC in normal subjects. Psychopharmacology. 1982;76:245-50.

11. Bhattacharyya S, Morrison PD, Fusar-Poli P, Martin-Santos R, Borgwardt S, Winton-Brown T, et al. Opposite effects of delta-9-tetrahydrocannabinol and cannabidiol on human brain function and psychopathology. Neuropsychopharmacology. 2010;35:764-74

12. Englund A, Morrison PD, Nottage J, Hague D, Kane F, Bonaccorso S, et al. Cannabidiol inhibits THC-elicited paranoid symptoms and hippocampaldependent memory impairment. J Psychopharmacol. 2013;27:19-27.

13. Iseger TA, Bossong MG. A systematic review of the antipsychotic properties of cannabidiol in humans. Schizophr Res. 2015;162:153-61.

14. Zuardi AW, Crippa JA, Hallak JEC, Bhattacharyya S, Atakan Z, Martin-Santos $R$, et al. A critical review of the antipsychotic effects of cannabidiol: 30 years of a translational investigation. Curr Pharm Des. 2012;18:5131-40.

15. BMC. Bureau Medicinale Cannabis (BMC; Office Medicinal Cannabis) of the Dutch Ministry of Health, Welfare and Sports (WWS). Specification sheet Bedrocan-Bedrobinol-Bediol-Bedica-Bedrolite. 2014. http://tinyurl.com/yc4637sf.

16. Wald FDM, Mellenberg GJ. De verkorte versie van de Nederlandse vertaling van de Profile of Mood States (POMS). [The shortened version of the Dutch translation of the Profile of Mood States (POMS). Nederlands Tijdschrift voor Psychologie Grensgebieden. 1990;45:86-90.

17. Rigter $\mathrm{S}$, Niesink R. THC-concentraties in wiet, nederwiet en hasj in Nederlandse coffeeshops (2015-2016). Utrecht: Trimbos instituut; 2016. https://assets.trimbos.nl/docs/dbf8d64a-8b91-4d05-9313-051e592c424b.pdf Accessed 31 May 2018

18. Schipper R, Schipper R, Dekker M, Dekker M, de Haan L, de HL et al. Medicinal cannabis (Bedrolite) substitution therapy in inpatients with a psychotic disorder and a comorbid cannabis use disorder: a case series. J Psychopharmacol 2017;32:353-356.
Ready to submit your research? Choose BMC and benefit from:

- fast, convenient online submission

- thorough peer review by experienced researchers in your field

- rapid publication on acceptance

- support for research data, including large and complex data types

- gold Open Access which fosters wider collaboration and increased citations

- maximum visibility for your research: over $100 \mathrm{M}$ website views per year

At $\mathrm{BMC}$, research is always in progress.

Learn more biomedcentral.com/submissions 